\title{
The Burden of Hypertension and Associated Factors Among Adults Visiting the Adult Outpatient Department at Yekatit 12 Hospital Medical College, Addis Ababa, Ethiopia, 2016
}

This article was published in the following Dove Press journal:

Vascular Health and Risk Management

\section{Daniel Awraris Berhe \\ Melaku Kindie Yenit (iD \\ Adhanom Gebreegziabher \\ Baraki (D) \\ Department of Epidemiology and Biostatistics, Institute of Public Health, College of Medicine and Health Sciences, University of Gondar, Gondar, Ethiopia}

Correspondence: Adhanom

Gebreegziabher Baraki

Tel +251918068580

Email adsh04@gmail.com
Background: Hypertension is a global health concern that can lead to cardiovascular disease and death. In Ethiopia, the risks for cardiovascular disease have been increasing dramatically. But due to the high burden of communicable diseases, less emphasis is given to noncommunicable diseases like hypertension. This study aimed to fill the information gap by determining the prevalence and the key determinants of hypertension in the study area.

Methods: Institution-based cross-sectional study was conducted in Yekatit 12 Hospital Medical College, Addis Ababa, Ethiopia from September to October 2016. A total of 414 adults visiting medical OPDs were selected using systematic random sampling. Data were collected by blood pressure measurements and a pre-tested structured questionnaire. Descriptive statistics were computed. Multivariable logistic regression analysis was used to determine the adjusted odds ratio with a $95 \%$ confidence interval. The goodness of fit of the model was also checked by Hosmer and Lemeshow test.

Results: The overall prevalence of hypertension in the study area was $38.9 \%(95 \% \mathrm{CI}$ : 34.1-43.7). Age above 55 years (AOR $=3.33$, 95\% CI: 1.88-5.90), family history of hypertension $(\mathrm{AOR}=2.71,95 \% \mathrm{CI}: 1.37-5.36)$, diabetes $(\mathrm{AOR}=4.15,95 \% \mathrm{CI} 1.77-9.72)$, obesity $(\mathrm{AOR}=5.50,95 \% \mathrm{CI}: 2.07-14.62)$, knee arthritis $(\mathrm{AOR}=1.71,95 \% \mathrm{CI}: 1.24,2.36)$, and not walking at least for 10 minutes continuously on daily basis ( $\mathrm{AOR}=2.86,95 \% \mathrm{CI}$ : $1.15-7.12$ ) were found to be independent predictors of hypertension.

Conclusion: Prevalence of hypertension was high in the study area, and a large proportion of them were also newly diagnosed. Factors like age, family history of hypertension, diabetes, obesity, knee arthritis, and exercise were found to be independent predictors of hypertension. Therefore, we recommend people who have these risk factors to have screening for hypertension.

Keywords: prevalence, hypertension, institution-based cross-sectional

\section{Background}

Hypertension is a global health concern. It can lead to severe complications and increases the risk of heart disease, stroke, and death. Hypertension affects an estimated 1.13 billion people worldwide, two-third of this lives in low and middleincome countries. ${ }^{1}$ The disease is also increased in economically developing countries, most countries in Africa, in recent years; while it remained stable or decreased in developed countries ${ }^{2}$ The pooled prevalence of hypertension in sub-Saharan 
Africa was $30 \%$ in $2013 .^{3}$ Institution-based studies in Ethiopia show the prevalence of hypertension to range from $7 \%$ to $37 \%$ and $37-78 \%$ of the patients are not aware of their blood pressure (BP) condition. ${ }^{4}$

The complications of hypertension account for 9.4 million deaths worldwide every year. ${ }^{5}$ Hypertension has been an important risk factor for coronary heart disease, congestive heart failure, ischemic and hemorrhagic stroke, renal failure, and peripheral arterial diseases. ${ }^{4,6,7}$

Among the commonly known risk factors for this catastrophic disease some are modifiable like obesity, physical activity, diet, smoking, alcohol consumption, and diabetes mellitus whereas some of them are not amenable to change, these include gender, age, genetics, and race. ${ }^{8-12}$

In Ethiopia, the risk of cardiovascular disease has been increasing alarmingly in recent years. ${ }^{13}$ But due to the high burden of communicable disease, less emphasis has been given to non-communicable diseases like hypertension. This study was aimed to fill this information gap by determining the prevalence and the key determinants of hypertension in the study area.

\section{Methods}

\section{Study Design and Setting}

An institution-based cross-sectional study was conducted in Yekatit 12 Hospital Medical College, Addis Ababa, Ethiopia from September 2016 to October 2016. Yekatit 12 Hospital Medical College was established in 1922 G.C. It has been providing service to the community for the past 94 years. It is the third oldest hospital in Addis Ababa next to Minillik II and Balcha hospitals. It has a catchment population of over 20 million with over 800 outpatient visits daily and 750 inpatient beds. Patients older than 14 years of age are treated at the adult wing of the hospital.

\section{Sample Size and Sampling Procedure}

The minimum sample size, 423, was calculated with the following assumptions: $\mathrm{P}=0.5,95 \%$ confidence interval, $5 \%$ margin of error, and 10\% non-response rate. These adult patients aged above 25 years old attending the adult medical outpatient departments (OPDs) for various reasons were included in the study. The study participants were selected by systematic random sampling.

\section{Data Collection Tools and Procedures}

Trained research assistants performed the measurements and administered a pre-tested structured questionnaire.
Blood pressure was measured using an adult size Mercury sphygmomanometer while the patient was in a sitting position from the left arm after the patient rested for at least 5 minutes before measurement. Two measurements of BP in a single visit were taken at least five minutes apart and the average of the two records was used to classify the blood pressure. Height was measured by using a stadiometer while the patient was in an upright position without wearing shoes. Weight was measured using a digital weighing scale with a precision of $0.1 \mathrm{~kg}$. The scale was calibrated to zero levels before each measurement. Waist circumference was measured by using a flexible tape meter at both the levels just above the iliac crest at the maximum circumference of the hip.

\section{Variables of the Study}

Hypertension, the dependent variable, was defined as a self-reported physician diagnosis of hypertension, or use of antihypertensive medication, or systolic BP (SBP) $\geq 140 \mathrm{~mm} \mathrm{Hg}$ and/or diastolic BP (DBP) $\geq 90 \mathrm{~mm} \mathrm{Hg.}{ }^{14,15}$

Independent variables considered were sociodemographic and Socioeconomic Factors such as age, sex, residence, educational status, religion, ethnicity occupation, and monthly income; Factors related to hypertension like Family history of hypertension, diabetes, arthritis; Behavioral Factors including Alcohol consumption, cigarette smoking, physical inactivity, and salt consumption.

A participant is labeled as an excessive salt user than his/her family member if he/she adds salt to the plate after the food is served.

The BMI of the patients was classified as Underweight $\left(\mathrm{BMI} \leq 18.49 \mathrm{~kg} / \mathrm{m}^{2}\right)$, normal weight (BMI 18.5-24.9 kg/m²), overweight (BMI 25.0-29.9 $\mathrm{kg} / \mathrm{m}^{2}$ ), and obese (BMI $\geq$ $30.0-39.9 \mathrm{~kg} / \mathrm{m}^{2.16}$

\section{Data Processing and Analysis}

Data were cleaned and entered into Statistical Package for Social Sciences (SPSS) version 20 for analysis. Descriptive statistics, including frequency and proportions, were computed to summarize the study variables. Both bivariable and multivariable logistic regression analyses were carried out. Variables with a p-value of less than 0.2 in the bivariable analysis were entered into the multivariable analysis. Both Crude Odds Ratio (COR) and Adjusted Odds Ratio (AOR) with a 95\% confidence interval were estimated to show the strength of association. Finally, a P-value of less than 0.05 in the multivariable 
logistic regression analysis was used as variables significantly associated with the occurrence of hypertension. The goodness of fit of the model was checked by Hosmer and Lemeshow test.

\section{Ethical Considerations}

Ethical approval and permission to conduct the study after verbal informed consent was obtained from the research and ethics review board of the University of Gondar. Verbal informed consent was obtained from participants after a comprehensive explanation of the purpose and procedure per the Declaration of Helsinki. To keep the privacy of participants', names and other personal identifiers were not collected.

\section{Results}

\section{Socio-Demographic and Economic Characteristics}

A total of 414 adults participated in the study making the response rate $97.9 \%$; more than half 219 (52.9\%) were females. The mean age was $45.3 \pm 12.7$ years. The majority of participants, 138 (33.3\%) were orthodox Christians, 248 (59.9\%) were married and $152(36.7 \%)$ were government employees (Table 1).

\section{Dietary and Exercise-Related Characteristics of Respondents}

More than ninety-six percent of the participants, 399 (96.4\%), reported that they usually use vegetable oil for meal preparation. Eighty-two (19.8\%) respondents have reported excessive use of salt than other family members. A larger proportion of participants, 263 (63.6\%), reported eating vegetables at least 1-3 days in the week before the survey. Half of the respondents 207 (50.1\%) do not eat fruits at all on any days of the previous week.

Sixteen participants $(3.9 \%)$ declared that they were smoking cigarettes previously. Fourteen participants (3.4\%) were current smokers of whom eight (57.1\%) were smoking at least five cigarettes per day. Regarding their alcohol consumption status, $184(44.4 \%)$ current users.

The average BMI of respondents was $19.87 \pm 9.23$. Forty-three (10.4\%) respondents were overweight whereas $39(9.4 \%)$ were obese. A large proportion of the study participants $244(58.9 \%)$ had no history of vigorous work activities such as carrying or lifting heavy loads or
Table I Socio-Demographic Characteristics of the Study Participants in Yekatit 12 Hospital Medical College, Addis Ababa, Ethiopia-2016

\begin{tabular}{|c|c|c|}
\hline Characteristics & Frequency & Percentage \\
\hline \multicolumn{3}{|l|}{ Marital status } \\
\hline Married & 248 & 59.9 \\
\hline Single & 48 & 11.6 \\
\hline Divorced & 51 & 12.3 \\
\hline Widowed/widower & 67 & 16.2 \\
\hline \multicolumn{3}{|l|}{ Educational level } \\
\hline No formal education & 70 & 16.9 \\
\hline Primary level & 109 & 26.3 \\
\hline Secondary level & 113 & 27.3 \\
\hline Tertiary level & 122 & 29.5 \\
\hline \multicolumn{3}{|l|}{ Occupation } \\
\hline Government employee & 152 & 36.7 \\
\hline Private employee & 94 & 22.7 \\
\hline Merchant & 60 & 14.5 \\
\hline Housewife & 25 & 6.0 \\
\hline Retired & 60 & 14.5 \\
\hline Others* & 23 & 5.6 \\
\hline \multicolumn{3}{|l|}{ Religion } \\
\hline Orthodox & 138 & 33.3 \\
\hline Muslim & 109 & 26.3 \\
\hline Protestant & 99 & 23.9 \\
\hline Catholic & 60 & 14.5 \\
\hline Jehovah witness & 8 & 1.9 \\
\hline \multicolumn{3}{|l|}{ Ethnicity } \\
\hline Amhara & 122 & 27.1 \\
\hline Oromo & 126 & 30.4 \\
\hline Tgrie & 76 & 18.4 \\
\hline Gurage & 90 & 21.7 \\
\hline Others** & 10 & 2.4 \\
\hline \multicolumn{3}{|l|}{ Monthly income } \\
\hline$\leq 750$ & 43 & 10.4 \\
\hline $751-1300$ & 99 & 23.9 \\
\hline$|30|-2000$ & 106 & 25.6 \\
\hline$>2000$ & 166 & 40.1 \\
\hline
\end{tabular}

Notes: *Students and daily laborers; **Dorze, Silte and Somali.

construction works. But most participants 375 (91.5\%) walks for at least 10 minutes continuously every day (Table 2).

\section{The Prevalence of Hypertension}

The overall prevalence of hypertension was $38.9 \%$ (95\% CI: 34.1-43.7). Among all hypertensive people identified, 72 (44.7\%) did not know they had hypertension (newly screened) and the other $89(55.3 \%)$ were on antihypertensive 
Table 2 Dietary and Exercise-Related Characteristics of the Study Participants in Yekatit 12 Hospital Medical College, Addis Ababa, Ethiopia-2016

\begin{tabular}{|c|c|c|}
\hline Characteristics & Number & Percentage \\
\hline \multicolumn{3}{|l|}{ Smoking } \\
\hline Never & 384 & 92.8 \\
\hline Current & 14 & 3.4 \\
\hline Previous & 16 & 3.9 \\
\hline \multicolumn{3}{|l|}{ Alcohol use } \\
\hline Never & 195 & 47.1 \\
\hline Current & 184 & 44.4 \\
\hline Previous & 35 & 8.5 \\
\hline \multicolumn{3}{|l|}{ Commonly used oil/fat } \\
\hline Vegetable oil & 399 & 96.4 \\
\hline Butter/Ghee & 15 & 3.6 \\
\hline \multicolumn{3}{|l|}{ Fruit consumption/week } \\
\hline None & 207 & 50.1 \\
\hline I-3 days & 155 & 37.4 \\
\hline 4-7 days & 52 & 12.6 \\
\hline \multicolumn{3}{|l|}{ Vegetable use/week } \\
\hline None & 46 & II.I \\
\hline I-3 days & 263 & 63.6 \\
\hline 4-7 days & 105 & 25.4 \\
\hline \multicolumn{3}{|l|}{ Excessive salt } \\
\hline Yes & 82 & 19.8 \\
\hline No & 332 & 80.2 \\
\hline \multicolumn{3}{|l|}{ Vigorous work/week } \\
\hline None & 244 & 58.9 \\
\hline I-3 days & 98 & 23.7 \\
\hline 4-7 days & 72 & 17.4 \\
\hline \multicolumn{3}{|l|}{ Walking for 10 minutes } \\
\hline None & 25 & 6.0 \\
\hline Daily & 375 & 91.5 \\
\hline Less than 5 days per week & 14 & 3.4 \\
\hline \multicolumn{3}{|l|}{ Diabetes status } \\
\hline Yes & 38 & 90.6 \\
\hline No & 375 & 9.4 \\
\hline \multicolumn{3}{|l|}{ Family History of hypertension } \\
\hline Yes & 53 & 12.8 \\
\hline No & 296 & 71.5 \\
\hline I do not know & 65 & 15.7 \\
\hline
\end{tabular}

treatment. The burden of hypertension has also shown a notable difference by age of the participants (Figure 1).

\section{Factors Associated with Hypertension}

Among the non-modifiable risk factors, age, and family history of hypertension were found to be significantly

\section{Prevalence of hypertension}

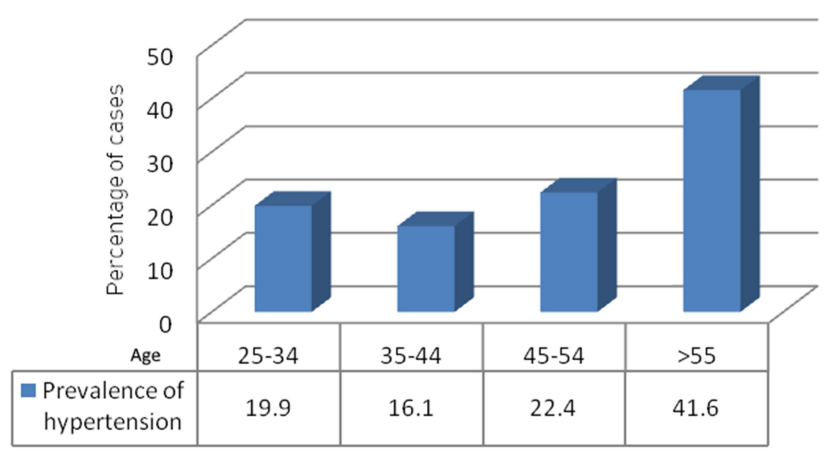

Figure I The prevalence of hypertension by age of study participants in Yekatit 12 hospital medical college, 2016.

associated with hypertension. On the other hand, having diabetes, walking for 10 minutes daily, obesity, and selfreported knee arthritis were independently associated with hypertension. Participants who are equal or above 55 years old had a higher odds of developing hypertension when compared with those in the age group of 25 to 34, with an AOR of 3.33 [95\% CI: 1.88-5.90].

Patients who had a family history of hypertension had 2.71 times $(\mathrm{AOR}=2.71$ and $95 \% \mathrm{CI}, 1.37-5.36)$ higher odds of having hypertension compared to their counterparts.

The odds of having hypertension was 4.15 times higher among patients who had diabetes ( $\mathrm{AOR}=4.15$ and $95 \% \mathrm{CI}$ 1.77-9.72) than the non-diabetes.

Participants who did not walk at least for 10 minutes continuously on daily basis had 2.86 times $(\mathrm{AOR}=2.86$ and $95 \%$ CI $1.15-7.12$ ) higher odds of being hypertensive when compared with those who did. The odds of being hypertensive among obese participants was 5.5 times (AOR=5.50 and 95\% CI: 2.07-14.62) higher as compared to those who have normal BMI.

Participants with self-reported knee arthritis also had a $71 \%$ increased odds of developing hypertension as compared to those without knee arthritis $(\mathrm{AOR}=1.71 ; 1.24$, 2.36) (Table 3).

\section{Discussion}

This study institution-based cross-sectional determined the prevalence of hypertension and associated factors and found a prevalence of $38.9 \%$. We also found that a large proportion of the hypertension cases were undiagnosed and thus untreated. The prevalence of hypertension in our study is in line with studies conducted in North India 
Table 3 Bivariable and Multivariable Logistic Regression Result of Factors Associated with Hypertension Among Study Participants in Yekatit 12 Hospital Medical College, 2016

\begin{tabular}{|c|c|c|c|c|}
\hline \multirow[t]{2}{*}{ Variables } & \multicolumn{2}{|c|}{ Hypertension } & \multirow[t]{2}{*}{ COR $(95 \% \mathrm{Cl})$} & \multirow[t]{2}{*}{ AOR (95\% CI) } \\
\hline & Yes & No & & \\
\hline \multicolumn{5}{|l|}{ Age } \\
\hline $25-34$ & 32 & 73 & 1.00 & 1.00 \\
\hline $35-44$ & 26 & 68 & $0.18(0.08-2.89)$ & $1.25(0.52-2.98)$ \\
\hline $45-54$ & 36 & 72 & $1.72(1.05-2.80)$ & I.4I (0.74-2.69) \\
\hline$\geq 55$ & 67 & 40 & $4.27(2.82-6.47)$ & 3.33 (1.88-5. 90)* \\
\hline \multicolumn{5}{|l|}{ Educational level } \\
\hline No formal education & 24 & 46 & 1.00 & 1.00 \\
\hline Primary level & 29 & 80 & $0.71(0.46-1.10)$ & $0.61(0.3 \mid-1.22)$ \\
\hline Secondary level & 26 & 87 & $0.59(0.38-0.91)$ & $0.89(0.44-1.8 I)$ \\
\hline Tertiary level & 27 & 95 & $0.53(0.31-0.89)$ & $0.85(0.34-2.11)$ \\
\hline \multicolumn{5}{|l|}{ Marital status } \\
\hline Married & 57 & 191 & 1.00 & 1.00 \\
\hline Single & 13 & 35 & $0.76(0.43-1.33)$ & $0.53(0.23-1.24)$ \\
\hline Divorced & 11 & 40 & $0.69(0.35-1.36)$ & $0.52(0.20-1.38)$ \\
\hline Widowed & 30 & 37 & $2.01(1.10-3.68)$ & $0.77(0.31-1.89)$ \\
\hline \multicolumn{5}{|l|}{ Occupation } \\
\hline Gov't employee & 31 & 121 & 1.00 & 1.00 \\
\hline Private employee & 78 & 16 & $1.09(0.58-2.05)$ & $1.02(0.37-2.85)$ \\
\hline Merchant & 13 & 47 & $0.81(0.40-1.64)$ & I.I8 (0.37-3.76) \\
\hline House wife & 9 & 16 & $2.20(1.28-3.76)$ & $1.33(0.52-3.44)$ \\
\hline Retired & 24 & 36 & $2.58(1.32-5.03)$ & $0.92(0.29-2.90)$ \\
\hline Others* & 6 & 17 & $1.43(0.60-3.39)$ & $1.05(0.21-5.13)$ \\
\hline \multicolumn{5}{|l|}{ Body Mass Index } \\
\hline Normal & 57 & 168 & 1.00 & 1.00 \\
\hline Underweight & 63 & 44 & $0.49(0.24-0.99)$ & $0.50(0.22-1.16)$ \\
\hline Overweight & 15 & 28 & $1.50(1.02-2.21)$ & $1.57(0.93-2.64)$ \\
\hline Obese & 26 & 13 & $4.52(2.27-9.01)$ & $5.50(2.07-14.62)^{*}$ \\
\hline \multicolumn{5}{|l|}{ Self-reported Diabetes } \\
\hline Yes & 27 & 11 & $5.67(3.02-10.64)$ & $4.15(1.77-9.72) *$ \\
\hline No & 134 & 242 & 1.00 & 1.00 \\
\hline \multicolumn{5}{|c|}{ Family history of hypertension } \\
\hline Yes & 33 & 20 & $2.27(\mathrm{I} .4 \mathrm{I}-3.64)$ & $2.71(1.37-5.36)^{*}$ \\
\hline No & 73 & 223 & 1.00 & 1.00 \\
\hline I do not know & 9 & 56 & $0.80(0.46-1.40)$ & $0.70(0.30-1.65)$ \\
\hline \multicolumn{5}{|c|}{ Self-reported Knee Arthritis } \\
\hline Yes & 26 & II & $2.82(1.09-5.32)$ & $1.71(1.24-2.36)^{*}$ \\
\hline No & 135 & 242 & $1.60(0.86-2.98)$ & $3.89(0.69-7.32)$ \\
\hline \multicolumn{5}{|l|}{ Walking for 10 minutes } \\
\hline None & 16 & 9 & $3.46(1.72-6.96)$ & $2.86(1.15-7.12)^{*}$ \\
\hline Daily & 143 & 232 & 1.00 & 1.00 \\
\hline$<5$ days per week & 2 & 12 & $0.5(0.28-0.74)$ & $1.25(0.36-2.2 I)$ \\
\hline
\end{tabular}

Note: $*$ P-value $<0.05$ 
$(40.1 \%),{ }^{17}$ and Nigeria $(42.2 \%) .{ }^{18}$ However, it is higher than studies done in Bahirdar city $16.45 \%{ }^{19}$ Jigjiga city $(28.3 \%),{ }^{20}$ Tanzania $(23.7 \%),{ }^{21}$ and South India $(30 \%) .{ }^{22}$ The possible reason for this discrepancy could be the socio-demographic difference of study participants especially the age distribution, and/or the difference in lifestyle.

This study has found an increase in the risk of hypertension as age increases. This finding is consistent with other studies conducted in Gondar ${ }^{11}$ Uganda $^{8} \operatorname{Jordan}^{10}$ and Nepal. ${ }^{23}$ This could be due to age-related changes in arterial and arteriolar stiffness, mainly due to arteriosclerotic structural alterations and calcification. ${ }^{24}$ But, the findings from this study also show a high burden of the disease in the young population for instance from 105 patients younger than 35 years 32 of them were hypertensive. This is an alarm that public health interventions should also target the young population for young people are prone to be engaged in other risks of hypertension like alcohol drinking and smoking.

The risk of having hypertension was also increased in obese patients as compared to those who have normal BMI. This finding is in line with other studies conducted in Durame, southern Ethiopia, ${ }^{9}$ Jigjiga city ${ }^{20}$ Uganda, ${ }^{8}$ and Varanasi India. ${ }^{25}$ Elevated arterial pressure or structural changes in the kidney secondary to obesity can also be a possible explanation for this association. ${ }^{26,27}$

Patients who had a family history of hypertension were also found to have more than a double increase in the risk of having hypertension as compared to their counterparts. This association was also seen in other similar studies $^{9,10,20,28}$ This could be due to the similarities of genes in blood relatives which can predispose them to high blood pressure, heart disease, and stroke or because family members tend to have a similar lifestyle and dietary habits that can predispose them for this disease..$^{29,30}$

According to our findings, diabetic patients had an increased risk of hypertension when compared to nondiabetic patients. This finding is supported by several other studies ${ }^{11,31,32}$ this could be due to the kidney damage made by diabetes leading to a high risk of cardiovascular disease including hypertension. ${ }^{33,34}$

Participants who had knee arthritis were found to have an increased risk of hypertension as compared to their counterparts. Studies have also found a similar association between the two diseases. ${ }^{35,36}$ This could be due to individuals who are overweight or obese are often diagnosed with arthritis which is caused by excessive pressure on their joints or the use of non-steroidal anti-inflammatory medications, NSAIDs, by these individuals. The use of NSAIDs can directly affect blood pressure readings. ${ }^{37}$

In this study, we have also found an increase in the risk of hypertension in patients who did not walk at least for 10 minutes continuously on daily basis as compared to those who did. Such associations were also seen in other studies $^{11,28,38}$ The reduction in blood pressure in individuals who walk for at least 10 minutes continuously daily could be due to attenuation in peripheral vascular resistance, which may be due to neurohormonal and structural responses with reductions in sympathetic nerve activity and an increase in arterial lumen diameters. ${ }^{39}$

\section{Limitations}

Since we checked the diabetes status of patients by an interview we might miss those who are diabetic but not diagnosed. The cross-sectional nature of the study may not also provide a strong cause-effect relationship. The relatively small sample size used may also affect the estimates.

\section{Conclusions}

We have found a high prevalence of hypertension in the study area and a large proportion of them was newly diagnosed and in the young population. Factors like age, family history of hypertension, diabetes, obesity, knee arthritis, walk at least for 10 minutes continuously on daily basis were found to be independent predictors of hypertension. Therefore in addition to the established annual screening recommendations, we suggest people who have the identified risk factors in this study to have screening for hypertension. Clinicians shall also consider the identified risk factors to suspect and apply screening for hypertension.

\section{Author Contributions}

All authors made a significant contribution to the work reported in the conception, study design, execution, acquisition of data, analysis, and interpretation, or in all these areas; took part in drafting, revising, or critically reviewing the article; gave final approval of the version to be published; have agreed on the journal to which the article has been submitted; and agreed to be accountable for all aspects of the work.

\section{Disclosure}

All authors declare that they have no conflict of interest in this work. 


\section{References}

1. World Health Organization. Hypertension; 2019. Available from: https://www.who.int/news-room/fact-sheets/detail/hypertension. Accessed November 28, 2020.

2. Kearney PM, Whelton M, Reynolds K, Whelton PK, He J. Worldwide prevalence of hypertension: a systematic review. J Hypertens. 2004;22 (1):11-19. doi:10.1097/00004872-200401000-00003

3. Ataklte F, Erqou S, Kaptoge S, Taye B, Echouffo-Tcheugui JB, Kengne AP. Burden of undiagnosed hypertension in sub-saharan Africa: a systematic review and meta-analysis. Hypertension. 2015;65(2):291-298. doi:10.1161/HYPERTENSIONAHA.114.04394

4. Legese N, Tadiwos Y. Epidemiology of hypertension in ethiopia: a systematic review. Integr Blood Press Control. 2020;13:135. doi:10.2147/IBPC.S276089

5. World Health Organization. Causes of Death 2008: Data Sources and Methods. Geneva; 2011.

6. Lawes C, Bennett DA, Parag V, et al. Blood pressure indices and cardiovascular disease in the Asia Pacific region: a pooled analysis. Hypertension. 2003;42(1):69-75.

7. Sowers JR, Epstein M, Frohlich ED, Sowers JR, Epstein M, Frohlich ED. Diabetes, hypertension, and cardiovascular disease: an update. Hypertension. 2001;37(4):1053-1059. doi:10.1161/01. HYP.37.4.1053

8. Wamala JF, Karyabakabo Z, Ndungutse D, Guwatudde D. Prevalence factors associated with hypertension in Rukungiri district, Uganda-a community-based study. Afr Health Sci. 2009;9(3).

9. Helelo TP, Gelaw YA, Adane AA. Prevalence and associated factors of hypertension among adults in Durame Town, Southern Ethiopia. PLoS One. 2014;9(11):e112790. doi:10.1371/journal.pone.0112790

10. Jaddou H, Batiehah A, Ajlouni K. Prevalence and associated factors of hypertension: results from a three community-based survey, Jordan. J Hum Hypertens. 1996;10(12):815-821.

11. Awoke A, Awoke T, Alemu S, Megabiaw B. Prevalence and associated factors of hypertension among adults in Gondar, Northwest Ethiopia: a community based cross-sectional study. BMC Cardiovasc Disord. 2012;12(1):113. doi:10.1186/1471-2261-12-113

12. Nuraini B. Risk factors of hypertension. J Majority. 2015;4(5).

13. Tran A, Gelaye B, Girma B, et al. Prevalence of metabolic syndrome among working adults in Ethiopia. Int J Hypertens. 2011;2011.

14. Whitworth JA. Blood pressure and control of cardiovascular risk. Vasc Health Risk Manag. 2005;1(3):257.

15. Egan BM, Zhao Y, Axon RN. US trends in prevalence, awareness, treatment, and control of hypertension, 1988-2008. JAMA. 2010;303 (20):2043-2050. doi:10.1001/jama.2010.650

16. Akram DS, Astrup AV, Atinmo T, et al. Obesity: preventing and managing the global epidemic. Report of a WHO consultation. World Health Organ Tech Rep Ser. 2000;894:i-xii,1-253.

17. Tripathy JP, Thakur JS, Jeet G, Chawla S, Jain S. Alarmingly high prevalence of hypertension and pre-hypertension in North India-results from a large cross-sectional STEPS survey. PLoS One. 2017;12(12):e0188619. doi:10.1371/journal.pone.0188619

18. Ulasi II, Ijoma CK, Onwubere BJ, Arodiwe E, Onodugo O, Okafor C. High prevalence and low awareness of hypertension in a market population in Enugu, Nigeria. Int J Hypertens. 2011;2011.

19. Kasa AS, Shifa AK. Prevalence and assessment of knowledge and practice towards hypertension among Bahir Dar City communities, 2016: a community based cross-sectional study. Int J Nurs Midwifery. 2017;9(3):33-40. doi:10.5897/IJNM2016.0231

20. Asresahegn H, Tadesse F, Beyene E. Prevalence and associated factors of hypertension among adults in Ethiopia: a community based cross-sectional study. BMC Res Notes. 2017;10(1):629. doi:10.1186/s13104-017-2966-1
21. Muhihi A, Njelekela M, Mpembeni R, et al. Physical activity and cardiovascular disease risk factors among young and middleaged men in urban Mwanza, Tanzania. Pan Afr Med J. 2012;11(1).

22. Thomas AM, Reshma RA. Prevalence of hypertension and associated risk factors among patients attending outpatient department of a teaching hospital in central Kerala. Hypertension. 140:90.

23. Dhungana RR, Pandey AR, Bista B, Joshi S, Devkota S. Prevalence and associated factors of hypertension: a community-based cross-sectional study in municipalities of Kathmandu, Nepal. Int J Hypertens. 2016;2016.

24. Pinto E. Blood pressure and ageing. Postgrad Med J. 2007;83 (976):109-114. doi:10.1136/pgmj.2006.048371

25. Singh S, Shankar R, Singh GP. Prevalence and associated risk factors of hypertension: a cross-sectional study in urban Varanasi. Int J Hypertens. 2017;2017.

26. Hall JE, Crook ED, Jones DW, Wofford MR, Dubbert PM. Mechanisms of obesity-associated cardiovascular and renal disease. Am J Med Sci. 2002;324(3):127-137. doi:10.1097/00000441200209000-00003

27. Re RN. Obesity-related hypertension. Ochsner J. 2009;9(3):133-136.

28. Giday A, Tadesse B. Prevalence and determinants of hypertension in rural and urban areas of southern Ethiopia. Ethiop Med J. 2011;49 (2):139-147

29. Corvol P, Jeunemaitre X, Charru A, Soubrier F. Can the genetic factors influence the treatment of systemic hypertension? The case of the renin-angiotensin-aldosterone system. Am J Cardiol. 1992;70 (12):D14-D20. doi:10.1016/0002-9149(92)90267-3

30. Carmelli D, Robinette D, Fabsitz R. Concordance, discordance and prevalence of hypertension in World War II male veteran twins. $J$ Hypertens. 1994;12(3):323-328. doi:10.1097/00004872199403000-00015

31. Tamiru S, Alemseged F. Risk factors for cardiovascular diseases among diabetic patients in southwest Ethiopia. Ethiop J Health Sci. 2010;20(2).

32. Rodrigues Barbosa A, Ferreti Borgatto A. Arterial hypertension in the elderly of Bridgetown, Barbados: prevalence and associated factors. $J$ Aging Health. 2010;22(5):611-630. doi:10.1177/ 0898264310371123

33. Sarnak MJ, Levey AS, Schoolwerth AC, et al. Kidney disease as a risk factor for development of cardiovascular disease: a statement from the American heart association councils on kidney in cardiovascular disease, high blood pressure research, clinical cardiology, and epidemiology and prevention. Circulation. 2003;108 (17):2154-2169. doi:10.1161/01.CIR.0000095676.90936.80

34. Haroun MK, Jaar BG, Hoffman SC, Comstock GW, Klag MJ, Coresh J. Risk factors for chronic kidney disease: a prospective study of 23,534 men and women in Washington County, Maryland. $J$ Am Soc Nephrol. 2003;14(11):2934-2941. doi:10.1097/01. ASN.0000095249.99803.85

35. Y-M Z, Wang J, Liu X-G. Association between hypertension and risk of knee osteoarthritis: a meta-analysis of observational studies. Medicine. 2017;96(32).

36. Dessein PH, Joffe BI, Veller MG, et al. Traditional and nontraditional cardiovascular risk factors are associated with atherosclerosis in rheumatoid arthritis. $J$ Rheumatol. 2005;32(3):435-442.

37. Aljadhey H, Tu W, Hansen RA, Blalock SJ, Brater DC, Murray MD. Comparative effects of non-steroidal anti-inflammatory drugs (NSAIDs) on blood pressure in patients with hypertension. $B M C$ Cardiovasc Disord. 2012;12(1):93. doi:10.1186/1471-2261-12-93

38. Tesfaye F, Byass P, Wall S. Population based prevalence of high blood pressure among adults in Addis Ababa: uncovering a silent epidemic. BMC Cardiovasc Disord. 2009;9(1):39.

39. Hamer M. The anti-hypertensive effects of exercise. Sports Med. 2006;36(2):109-116. doi:10.2165/00007256-200636020-00002 


\section{Publish your work in this journal}

Vascular Health and Risk Management is an international, peerreviewed journal of therapeutics and risk management, focusing on concise rapid reporting of clinical studies on the processes involved in the maintenance of vascular health; the monitoring, prevention and treatment of vascular disease and its sequelae; and the involvement of metabolic disorders, particularly diabetes. This journal is indexed on PubMed Central and MedLine. The manuscript management system is completely online and includes a very quick and fair peerreview system, which is all easy to use. Visit http://www.dovepress com/testimonials.php to read real quotes from published authors. 